\title{
A NEW APPROACH FOR RESOLVING A SUPPLIER SELECTION AND EVALUATION PROBLEM
}

\author{
Raouf Ketata, Hajer Ben Mahmoud, Taieb Ben Romdhan \\ National Institute of Applied Science and Technology INSAT: Northern Urban Centres 1080 Tunis \\ Tel: (00216) 71.703.829, Fax: (00216) 71.704.329 \\ E-mail addresses: raouf.ketata@insat.rnu.tn,hamden_bm@yahoo.fr, tbr.tim@planet.tn
}

\begin{abstract}
In order to select the best suppliers it is necessary to make a trade off between these tangible and intangible factors some of which may conflict. This article proposes a new approach based on the integration of the fuzzy logic with the classical multi-criteria methods on the one hand and taking into account the concept of supplier reliability for resolving a supplier selection and evaluation problem on the other hand. Indeed, we deal with the first approach called "Method with Constraints" (MC) which consists of combination of the "Fuzzy Analytical Hierarchy Process" (FAHP) with the "Goal Programming" (GP) methods. This method reflects the idea of supplier reliability and at the same time the quantitative and qualitative factors. Considering the fuzzy constraints, we propose the second approach called "Method with Fuzzy Constraint" (MCF) which consists of combination of the FAHP with the "Fuzzy Goal Programming" (FGP) methods. We used the gravity centre method to approach the best solution, the supplier reliability approach to identify the most reliable supplier and the fuzzy logic method to find solutions for the inaccuracy and uncertainty problems.

A numerical example is presented to illustrate this new approach which includes comparing the advantages and disadvantages of the selection methods for resolving a supplier selection and evaluation problem.
\end{abstract}

\section{Keywords: Fuzzy logic, fuzzy multi-criteria method, decision making aid, selection and evaluation.}

\subsection{INTRODUCTION}

In general, when we want to tackle a problem that has no solution for all the criteria, use of multi-criteria methods [5] should be considered. These multi-criteria methods are believed to be able to provide us with better solutions [6]. The achievement of a solution is hardly attainable for the supplier selection and evaluation problems. To solve these problems, the authors used the multi-criteria analysis methods [1].

"Analytical Hierarchy Process" (AHP) is a decision-making method for prioritising alternatives when multiples criteria and sub-criteria need to be used. This method offers a methodology to rank alternative courses of action based on the decision's judgments concerning the importance of the criteria and the extent to which they are met by each alternative [13] and [14]. For this reason, AHP is ideally suitable to be used for the supplier selection problem. In addition, multi-criteria analysis methods permit users to make an evaluation and a selection based on its own perception of the relative various criteria importance. It allows identifying the strong and weak points of the supplier for improvement. This method can be used to identify particular fields in which available information's are insufficient [17].

In order to surmount this kind of problem, many researchers have considered to introduce the concept of combining the AHP [12] with the "Goal Programming" (GP) [3] methods. The combination of these methods was developed to take into account the qualitative and quantitative factors in supplier selection. However, this approach did not take into account other factors such as supplier reliability, absence of the personnel, delay or lack of raw materials, or violation of deadlines. In addition, decision-makers often find themselves facing problems choosing the best supplier. For these reasons, many researchers considered to use heuristic methods such as fuzzy logic [2], [10] and [11]. Often it is combined with AHP method and known as "Fuzzy Analytical Hierarchy Process" (FAHP) [15] and [7]. This methodology was characterized by the introduction of fuzzy logic at the measurements judgment i.e. the importance of the criteria. Therefore, this method has been developed to take account the qualitative and quantitative factors for decision making but this method ignores the concept reliability and the constraints posed for every problem. 
This paper is organized as follows. In Section 2, we summarize the most important methods used in the supplier selection and evaluation problem. In Section 3, we propose our new approach in solving the problem based on the integration of fuzzy logic with the multi-criteria methods and the supplier reliability concept. In Section 4, we present a numerical example for the new proposed approach. We then conclude our findings in Section 5.

\subsection{EXISTING METHODS FOR THE SUPPLIER SELECTION AND EVALUATION PROBLEM}

In this section, we discuss methods which can be used in the decision making process for supplier selection and evaluation problem.

\section{$2.1 \quad$ Multi-criteria methods}

Several multi-criteria methods have been applied for resolving the supplier selection and the evaluation problem. Popular approach used to solve this problem is called the AHP method proposed by L. Benyoucef et al. [8]. First, is to break a particular problem into a hierarchical system to define a tree hierarchical structure of criteria and under criteria [16]. It is distinguished by the determining criteria weights manner.

AHP method proceeds according to the following stages:

Stage 1. To define the problem

Stage 2. To break up the problem complexes in a hierarchical structure

Stage 3. To carry out the bit configurations

Stage 4. To determine the priorities

Stage 5. To synthesize the priorities

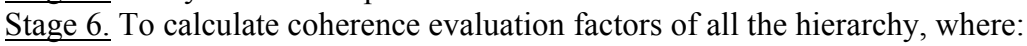

- $\quad$ Coherence Index (CI) is given by formula (1), and

- $\quad$ Ratio of Coherence (RC) is calculated by formula (2).

The more coherence the user judgements, the higher the Coherence Index (CI) will be, and vice versa. CI is given by the formula (1) as follows:

$$
C I=\frac{\lambda_{\max }-k}{k-1}
$$

Where $\mathrm{K}$ is the elements compared number and $\lambda$ is the average coherence value.

$\mathrm{RC}$ is defined by equation (2).

$$
R C=\frac{C I}{R I}
$$

The matrix is equivalent to the ratio between the Coherence Index (CI) and the Random Index (RI). Table 1 gives the values of RI according to the number of criteria.

Table 1 Random Index

\begin{tabular}{|c|c|c|c|c||c|c|}
\hline Number of criteria & 2 & 3 & 4 & 5 & 6 & 7 \\
\hline RI & 0 & 0.58 & 0.90 & 1.12 & 1.24 & 1.32 \\
\hline
\end{tabular}

We observed that the AHP method ignores the concept of constraint as well as the qualitative and quantitative factors regarding the supplier's choice. For this reason, the use of AHP and GP methods is considered [3]. If constraints such as production capacity of the supplier or the numbers of supplier required exist then we use the supplier estimate such as an objective function coefficient in GP method to assign command quantities to the supplier's selected.

The GP method stages are:

Stage 1. To define the variables and parameters of decision

Stage 2. To define the state constraints: $R_{x} \geq Q_{x}, Q_{x} \geq 0$, where the state constraints is given by formula (3), 


$$
\sum_{x=1}^{k i j} Q_{x}=T_{i j}
$$

Where,

$\mathrm{R}_{\mathrm{x}}$ : Production capacity for the supplier $\mathrm{x}$.

$\mathrm{Q}_{\mathrm{x}}$ : Purchase quantity of supplier $\mathrm{x}$.

$\mathrm{T}_{\mathrm{ij}}$ : Customer request for element $\mathrm{j}$ of product $\mathrm{i}$.

$\mathrm{k}_{\mathrm{ij}}$ : Total numbers potential solutions of replacement for the component $\mathrm{j}$ of product $\mathrm{i}$.

$\mathrm{x}$ : Supplier Index : $\mathrm{x}=1,2,3, \ldots, \mathrm{k}_{\mathrm{ij}}$.

Stage 3. To determine the priorities of pre-emption incorporating the weights found by AHP method:

- To maximize the Total Value of Purchase (TVP), and this is expressed by formula (4).

$$
\sum_{x=1}^{K_{i j}} W_{x}^{*} Q_{x}+U_{m}-E_{m}=T V P
$$

Where,

$\mathrm{W}_{\mathrm{x}}$ : AHP Weight for supplier $\mathrm{x}$.

$\mathrm{E}_{\mathrm{m}}$ : Top quantity of achievement for the goal $\mathrm{m}$.

$\mathrm{U}_{\mathrm{m}}$ : Lower quantity of achievement for the goal $\mathrm{m}$.

$\mathrm{m}$ : Priority Index: $\mathrm{m}=1,2,3, \ldots, \mathrm{M}$.

M: Goals number (priority).

- To minimize the Total Cost of Purchase (TCP), and it is given by formula (5).

$$
\sum_{x=1}^{K_{i j}} D_{x}^{*} Q_{x}+U_{n}-E_{n}=T C P
$$

Where,

$\mathrm{D}_{\mathrm{x}}$ : Unit cost of purchase for supplier $\mathrm{x}$.

n: Priority Index: $n=1,2,3, \ldots, N(\mathrm{~N}=\mathrm{M})$.

$\mathrm{N}$ : Goals number (priority).

Stage 4. To determine the state priorities: $P_{f}=\min \mathrm{U}_{\mathrm{f}}$ and $P_{f}^{2}=\min \mathrm{E}_{\mathrm{f}}(\mathrm{f}=\mathrm{m}$ or $\mathrm{f}=\mathrm{n})$.

The goal of the state top priority is to reduce the minimum of priority $P_{f}^{1}$ and $P_{f}^{2}$.

Stage 5. To find the optimal solution: The optimal solution decides which supplier (s) will be selected $\left(\forall \mathrm{x}, \mathrm{Q}_{\mathrm{x}}>0\right)$ and how many needed to ensure the optimal quantity $\left(\mathrm{Q}_{\mathrm{x}}{ }^{*}\right)$.

This approach does not take into account the supplier reliability and lets strict measurements judgments ${ }^{1}$.

\subsection{Fuzzy multi-criteria method}

The decision maker needs more and more precision in order to make good decision. So, some authors [15] proposed a multi-criteria aid decision methodology for the supplier selection and evaluation inspired by AHP method. The suggested method which called FAHP is characterized by the introduction of the fuzzy logic.

In contrast with AHP, where the decision maker can not provide deterministic preferences, the idea is based on the notion intervals. This type of uncertainty, whose preferences can be modelled, is employed by the fuzzy set theory. Indeed, mathematically modelled problems require too restrictive assumptions. So, compare to binary variables which are defined by the two states "True" and "False", the fuzzy variables present a whole gradation between the

1 The measurements judgements are expressed in terms of pair-wise comparisons of items on a given level of the hierarchy with respect to their impact on the next higher level. 
value "True" and the value "False". This approach has been developed by "Zadeh, (1965)" [9] based on its theory of the fuzzy subsets.

It is thus noted that this representation is much closer to the human reasoning, because it can employ the concepts of "Rather small" or "Rather large". In this new theory, an element which belongs to a fuzzy set can be modelled. Hence, the uncertainties reasoning (fuzzy) offers a flexibility which cannot be represented by traditional logic.

Indeed, a fuzzy subset $A$ of a discourse universe $X$ is defined as follow:

$\mathrm{A}=\left\{\mathrm{x} \in \mathrm{X}, \mu_{\mathrm{A}}(\mathrm{x})\right\}$

The membership function $\mu_{\mathrm{A}}$ characterizing the fuzzy subset $A$ of a discourse universe $X$ defined by:

$\mu_{\mathrm{A}}: \mathrm{X} \rightarrow[0,1]$

$\mathrm{x} \rightarrow \mu_{\mathrm{A}}(\mathrm{x})$.

To be able to make good decision, fuzzy logic introduction is done on the measurement judgment level. In overall terminology fuzzy set, the report provided by the decision maker is a fuzzy number described by a membership function. And in the same way, this method compares the suppliers with respect to this criterion in the same level, while allotting a numerical note. Under a numerical scale, Table 2 shows an example of fuzzy sets.

Table 2 Fuzzy measurements judgments

\begin{tabular}{|l|c|c|c|}
\hline \multicolumn{1}{|c|}{ Linguistic terms } & \multicolumn{3}{c|}{ Fuzzy sets } \\
\hline Equally Preferred (EP) & 1 & 1.5 & 2 \\
\hline Equally to Moderately Preferred (EMP) & 1.5 & 2 & 2.5 \\
\hline Moderately Preferred (MP) & 2 & 2.5 & 3 \\
\hline Moderately to Strongly Preferred (MSP) & 3 & 4.5 & 5 \\
\hline \hline Strongly Preferred (SP) & 4.5 & 5 & 6 \\
\hline Strongly to Very Strongly Preferred (SVSP) & 5.5 & 6.5 & 7 \\
\hline \hline Very Strongly Preferred (VSP) & 6.5 & 7.5 & 8 \\
\hline Very Strongly to Extremely Preferred (VSEP) & 7.5 & 8 & 8.5 \\
\hline \hline Extremely Preferred (ExP) & 8.5 & 9 & 9.5 \\
\hline
\end{tabular}

In contrast to AHP method, the measurements judgment provided by the maker decision is a fuzzy set. So the linguistic variable used for the resolution of our supplier selection and evaluation problem is the measurement having the following linguistic terms:

$\mathrm{T}($ measurement $)=\{$ EP, EMP, MP, MSP, SP, SVSP, VSP, VSEP, ExP $\}$. The discourse universe is defined in the interval $[1,9.5]$. Indeed, these linguistic terms were generated while being based on the measurements judgment.

Figure 1 shows the membership functions of these judgments. 


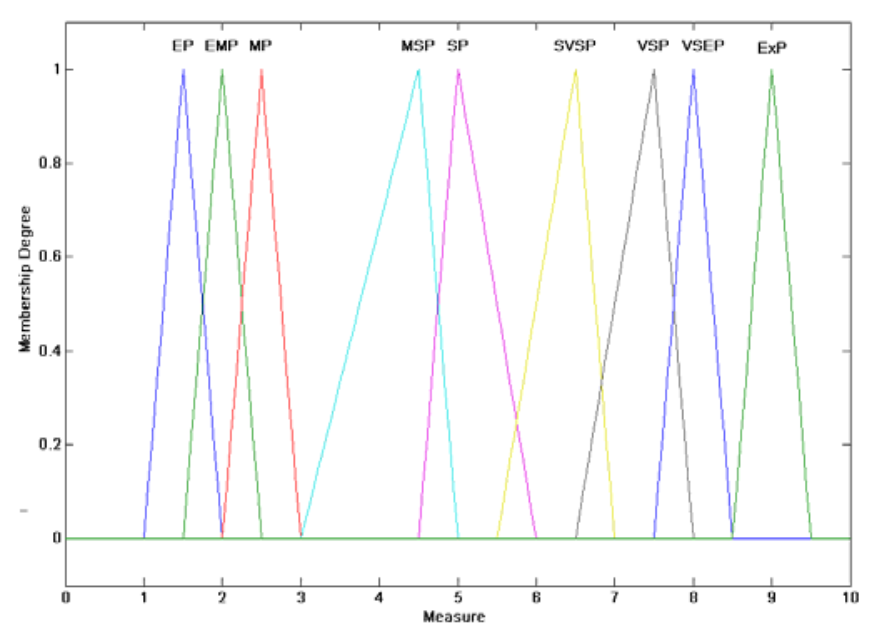

Fig. 1 Membership functions of measurements judgments

For example, a customer wants that the product quality is neither very important nor less important than the delivery time, i.e. Moderately Preferred. However, this judgment is not considered by AHP method because this method does not take into account the intermediate judgments. However, FAHP method allows the fuzzy numbers treatment, but it does not take into account the constraint and the external factors such as the absence of the personnel, non availability of machines, delay or lack of raw materials or violation of dead lines. Table 3 summarized the limitations of these methods.

Table 3 Sum up table

\begin{tabular}{|c|l|}
\cline { 2 - 2 } \multicolumn{1}{c|}{} & \multicolumn{1}{c|}{ Limitation } \\
\hline AHP & $\begin{array}{l}\text { The value presented by the decision maker is a strict } \\
\text { number. }\end{array}$ \\
\hline FAHP & Ignorant of constraint and exterior factor. \\
\hline $\begin{array}{c}\text { Combination AHP and } \\
\text { GP }\end{array}$ & Ignorant of supplier reliability. \\
\hline
\end{tabular}

\section{NEW APPROACHES}

To mitigate these limitations (as given Table 3), we propose of using two new approaches: Method with Constraint (MC) and its extension the Method with Fuzzy Constraint (MCF). We use the gravity centre method in order to approaching the best solution, the reliability method to support the most reliable supplier and the fuzzy logic for finding solutions for the inaccuracy and uncertainty problems.

\subsection{Method with Constraint (MC)}

The MC method combines the FAHP with GP method. So, the fuzzy logic will facilitate the measurements judgments for the decision makers and it will provide a precise description for the decision-making process. Each supplier has three notes ('Low' L, 'Average' A and 'High' H) and we want to conceive the fuzzy set to have only one note. For this reason, the notes found by FAHP method is treated by the 'gravity centre' application and is weakened by the "Discounting" application (reliability application). Knowing that each supplier depends on a certain constraints, consequently we should choose the GP method which takes into account all of these constraints.

\subsubsection{Determining the gravity centre method}

The gravity centre is a geometric property of any object. It is the point where all the object weight can be considered to be concentrated; so, it is the average location of the object weight. 
Each supplier has three notes $(\mathrm{L}, \mathrm{A}, \mathrm{H})$ and we want to conceive the fuzzy set to have only one note. For this reason, we will form a triangle by these three values. Indeed, the two "Low" and "High" values are the bases of triangle on the $\mathrm{X}$ axis and the value "Average" takes coordinated on the $\mathrm{Y}$ axis.

After the definition of coordinates triangle ( $\mathrm{X}$ and $\mathrm{Y}$ axis), we apply the gravity centre method. Figure 2 shows the gravity centre of a triangle which is the point of the medians contest, and it is given by:

'Low'+' Average'+' High'

3

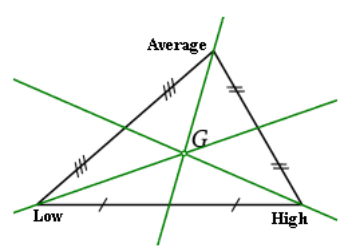

Fig. 2 Gravity centre method

This method gives us only one value and consequently it presents an indicator of decision making aid. In spite of the gravity centre use, FAHP method remains insufficient. Indeed, it comprises many criteria like the delivery time, the product quality and price, etc.... However, this method is not sufficient for choosing the best supplier.

For this reason, we called the "Discounting" method which is interested only in the supplier reliability (such as punctuality of the deliveries, the stability of the price or the supplier reputation on the market). Considering this precise and additional information, this method is used in order to judge the supplier reliability.

\subsubsection{Method treatment of reliability "Discounting”}

The "Discounting" method makes several surveys (or tests) in order to collect the maximum opinion on the supplier reliability. The idea is to retain the best and the bad probes. It is enough to call upon several experts in order to deliver specific opinions to each supplier. These experts must update their opinions at each period, because the reliability of supplier can change from one period to another. In order to obtain information about the adopted choice of the supplier, we apply the following formula (6).

For $\alpha \in[0,1]$, we have:

$$
\left\{\begin{array}{l}
\mathrm{D}(\text { reliable })=\alpha \\
\mathrm{D}(\text { unreliable })=1-\alpha
\end{array}\right.
$$

Where,

$\alpha$ : "Discounting" coefficient.

D: Reliability function.

The result consists in multiplying the probe report with the previously note found, given by the formula (7).

$$
\mathrm{D}(\mathrm{x})=\alpha * \mathrm{~N}(x)
$$

Where,

$\mathrm{N}$ : The final note of the supplier.

$\mathrm{x}$ : Supplier note.

\subsection{Method with Fuzzy Constraint (MCF)}

The MC method provided several satisfactory results. Better still, to improve the final decision, we proposed to combine the fuzzy logic with the GP method. So, and in order to fix the constraint imposed by the supplier, we carried out an extension of GP method called "Fuzzy Goal Programming" (FGP).

In contrast to GP method, where the various constraints are strict, the constraint provided by the supplier for FGP method are in the form of the fuzzy number described by a membership function.

Each supplier can not limit these constraints due to the presence of the external factors such as absence of the personnel, unavailability of the machines, or delay or the lack of the raw material. Hence, it is necessary to introduce fuzzy logic in these constraints. This logic is conceived to find the solution for the uncertainty problems and makes it possible to define sets in a more flexible way.

71

Malaysian Journal of Computer Science, Vol. 21(1), 2008 
Two fuzzy sets cases (as given in figure 3) are introduced as follows:

- If the fuzzy sets of the capacity production (example of constraint) given by the supplier have coincided then we should project the requested value of the customer so that we can choose the best supplier.

- If the fuzzy sets presented by the supplier have not coincided, then we will try to approach the best supplier. Indeed, if the required value is between two fuzzy sets, then we calculate the average between the maximum of the first interval and the minimum of the second. In this case, if the required value is between the maximum of the first interval and the average, then we chose the supplier of the first interval and vice versa.

Consequently, MCF method becomes a method which brings us closer towards the best decision.
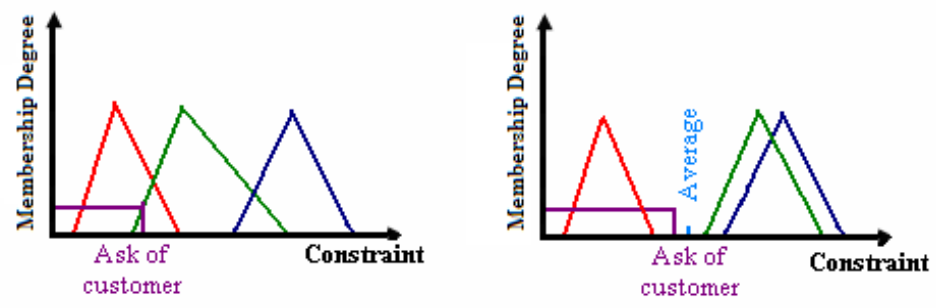

Fig. 3 Fuzzy sets treatment

\section{STUDY CASE}

Supplier selection and evaluation problem represents one of the most important functions to be performed by the purchasing department. The supplier selection is a multi-criterion problem which includes both qualitative and quantitative factors (criteria). In this section, we applied our new approaches (MC and MCF method) on a real example. A company (C) launches a tender to install a computer network which is to purchase several computers. For this, there are a lot of criteria that allow you to determine the best product. For this reason, the company (C) needs to fix its own criteria. From there, it will have several offers which then need to be sorted, and to choose the right supplier, where eventually making the right decision.

To solve this problem, it is necessary to go through by the following stages:

- To present the case facts.

- To build the criteria judgments matrix.

- To build the supplier judgments matrix.

- To calculate the supplier averages.

- To calculate the supplier averages with gravity centre.

- To treat the reliability "Discounting".

- To use the MC method for treatment.

- To use the MCF method for treatment.

\section{- Case facts}

For the computer purchase problem, the company fixes three major criteria which are the Quality of the product (Q), the Delivery time (D) and the Price (P), and three alternatives (Supplier) are presented which are: A, B, and C. Priorities of the criteria are announced as follows:

- The quality of the computer is strongly preferred than the delivery time.

- The quality of the computer is moderately preferred than the price.

- The price of the computer is moderately to strongly prefer than the delivery time.

The supplier's offers are presented in Table 4. 
Table 4 The supplier's offers

\begin{tabular}{|c|c|c|c|}
\hline Supplier & $\begin{array}{c}\text { Price } \\
\text { (Euro) }\end{array}$ & $\begin{array}{c}\text { Delivery times } \\
\text { (Days) }\end{array}$ & Quality \\
\hline A & 1000 & 2 & A is strongly to very strongly preferred than C \\
\hline B & 1350 & 9 & A is moderately to strongly preferred than B \\
\hline C & 1100 & 4 & C is moderately to strongly preferred than B \\
\hline
\end{tabular}

\section{- Criteria judgments matrix}

The problem is to choose one of the three suppliers by applying FAHP method. We start with filling the judgment matrix in the Table 5. For example, the quality of the product (criteria 1) is strongly preferred than the delivery time (criteria 2). This is translated by using the information in Table 2 (fuzzy set 4.5, 5 and 6).

Table 5 The judgments matrix for the criteria

\begin{tabular}{|c|c|c|c|c|c|c|c|c|c|}
\hline Objective & \multicolumn{4}{|c|}{ Q } & \multicolumn{3}{c|}{ D } & \multicolumn{3}{c|}{ P } \\
\hline $\mathbf{Q}$ & 1 & 1.5 & 2 & 4.5 & 5 & 6 & 2 & 2.5 & 3 \\
\hline $\mathbf{D}$ & $1 / 6$ & $1 / 5$ & $1 / 4.5$ & 1 & 1.5 & 2 & $1 / 5$ & $1 / 4.5$ & $1 / 3$ \\
\hline $\mathbf{P}$ & $1 / 3$ & $1 / 2.5$ & $1 / 2$ & 3 & 4.5 & 5 & 1 & 1.5 & 2 \\
\hline
\end{tabular}

Once this matrix is filled, we add the values with the same column, and then we divide each number of the column by this sum (see Mathematical formulation). These new values give a new matrix for which we calculate the average arithmetic numbers on each line. This step is repeated for filling every decision matrix.

Mathematical formulation:

Either A matrix equals to $\left[a_{i j}\right]$ with $i=1 \ldots n$ and $j=1 \ldots p$ with $a_{i j} \in R$ the matrix element located at the intersection of $\mathrm{i}^{\text {th }}$ row and $\mathrm{j}^{\text {th }}$ column.

$A=\left[\begin{array}{l}a_{11} a_{12} \ldots \ldots a_{1 p} \\ a_{n 1} a_{n 2} \ldots \ldots . a_{n p}\end{array}\right]$

The new matrix A' is the following form:

$\mathrm{A}^{\prime}=\left(\begin{array}{ccc}\frac{a_{11}}{S_{1}} & \frac{a_{12}}{S_{2}} & \frac{a_{1 p}}{S_{n}} \\ \frac{a_{n 1}}{S_{1}} & \frac{a_{n 2}}{S_{2}} & \frac{a_{n p}}{S_{n}}\end{array}\right]$

Where, $\mathrm{S}_{\mathrm{i}}$ : sum of each column and $\mathrm{R}_{\mathrm{j}}$ sum of each row.

\section{- Supplier judgments matrix}

We follows the same algorithm conduct (see mathematical formulation) and we treated the same way as before, then we can write new judgments matrix for each criterion (Tables 6,7 and 8). 
For

quality

product

For

delivery

time

For

Price product

Table 6 The judgments matrix for the criteria: Quality of product

\begin{tabular}{|c|c|c|c|c|c|c|c|c|c|}
\hline Supplier & \multicolumn{4}{|c|}{ A } & \multicolumn{3}{|c|}{ B } & \multicolumn{3}{c|}{ C } \\
\hline A & 1 & 1.5 & 2 & 3 & 4. & 5 & 5.5 & 6.5 & 7 \\
& & & & & 5 & & & & \\
\hline B & $1 /$ & $1 / 4$. & $1 / 3$ & 1 & 1. & 2 & $1 /$ & $1 / 4$. & $1 /$ \\
& 5 & 5 & & & 5 & & 5 & 5 & 3 \\
\hline C & $1 /$ & $1 / 6$. & $1 / 5$. & 3 & 4. & 5 & 1 & 1.5 & 2 \\
& 7 & 5 & 5 & & 5 & & & & \\
\hline
\end{tabular}

Table 7 The judgments matrix for the criteria: Delivery time

\begin{tabular}{|c|c|c|c|c|c|c|c|c|c|}
\hline Supplier & \multicolumn{4}{|c|}{ A } & \multicolumn{4}{|c|}{ B } & \multicolumn{3}{|c|}{ C } \\
\hline A & 1 & 1.5 & 2 & $\begin{array}{c}1 / \\
5\end{array}$ & $\begin{array}{c}1 / 4 . \\
5\end{array}$ & $1 / 3$ & 3 & 4. & 5 \\
& & & & 5 & & 5 & \\
\hline B & 3 & 4.5 & 5 & 1 & 1.5 & 2 & 4. & 5 & 6 \\
& & & & & & & 5 & & \\
\hline C & $1 /$ & $1 / 4$. & $1 /$ & $1 /$ & $1 / 5$ & $1 / 4$ & 1 & 1. & 2 \\
& 5 & 5 & 3 & 6 & & 5 & & 5 & \\
\hline
\end{tabular}

Table 8 The judgments matrix for the criteria: Price of product

\begin{tabular}{|c|c|c|c|c|c|c|c|c|c|}
\hline Supplier & \multicolumn{3}{|c|}{ A } & \multicolumn{3}{|c|}{ B } & \multicolumn{3}{|c|}{ C } \\
\hline A & 1 & 1.5 & 2 & $\begin{array}{c}1 / 2 . \\
5\end{array}$ & $\begin{array}{c}1 / \\
2\end{array}$ & $\begin{array}{c}1 / 1 . \\
5\end{array}$ & 3 & 4. & 5 \\
& & & & 5 & \\
\hline B & 1.5 & 2 & 2.5 & 1 & 1.5 & 2 & 4. & 5 & 6 \\
& & & & & & & 5 & & \\
\hline C & $1 /$ & $1 / 4$. & $1 /$ & $1 / 6$ & $1 /$ & $1 / 4$. & 1 & 1. & 2 \\
& 5 & 5 & 3 & & 5 & 5 & & 5 & \\
\hline
\end{tabular}

\section{- Supplier Average}

The implementation a FAHP algorithm for each supplier is led to calculate the notes for each alternative (as given in Table 9).

\begin{tabular}{|c|l|l|l|l|l|l|l|l|l|l|l|l|c|}
\hline Supplier & \multicolumn{3}{|c|}{ A } & \multicolumn{3}{c|}{ B } & \multicolumn{3}{c|}{ C } & \multicolumn{3}{|c|}{ Average } \\
\hline A & $\begin{array}{l}0.74 \\
5\end{array}$ & $\begin{array}{l}0.80 \\
0\end{array}$ & 0.795 & 0.429 & 0.429 & 0.417 & 0.822 & 0.791 & 0.751 & 0.665 & 0.673 & 0.654 \\
\hline B & $\begin{array}{l}0.14 \\
9\end{array}$ & $\begin{array}{l}0.11 \\
8\end{array}$ & 0.132 & 0.142 & 0.142 & 0.166 & 0.029 & 0.027 & 0.035 & 0.106 & 0.095 & 0.111 \\
\hline C & $\begin{array}{l}0.40 \\
9\end{array}$ & $\begin{array}{l}0.35 \\
0\end{array}$ & 0.371 & 0.429 & 0.429 & 0.417 & 0.149 & 0.214 & 0.214 & 0.329 & 0.331 & 0.334 \\
\hline
\end{tabular}

Table 9 Total priority vector 


\section{- Gravity centre}

For our example, the final values for our three suppliers are calculated, by applying the gravity center method and are given in Table 10.

Table 10 final values for three suppliers

\begin{tabular}{|c|c|}
\hline Supplier & $\begin{array}{c}\text { final } \\
\text { values }\end{array}$ \\
\hline A & 0.657 \\
\hline B & 0.109 \\
\hline C & 0.332 \\
\hline
\end{tabular}

We can not choose the first supplier immediately, because the suppliers have not the same degree of reliability. For this reason we will use the reliability method in order to support the most reliable supplier.

\section{- Reliability treatment "Discounting”}

For taking account of the expert's opinions (Avis) on the supplier reliability $(\alpha)$ which is represented in Table 11, we will apply the method "Discounting" to our example.

Table 11 Opinion for the supplier reliability

\begin{tabular}{|c|c|c|c|c|c|c|c|c|}
\hline Supplier & Avis & Avis & Avis & Avis & Avis & Avis & Avis & Avis \\
& $\mathbf{1}$ & $\mathbf{2}$ & $\mathbf{3}$ & $\mathbf{4}$ & $\mathbf{5}$ & $\mathbf{6}$ & $\mathbf{7}$ & $\mathbf{8}$ \\
\hline A & 0.2 & 0.1 & 0.3 & 0.2 & 0.5 & 0.2 & 0.3 & 0.4 \\
\hline B & 0.6 & 0.9 & 0.9 & 0.7 & 0.5 & 0.2 & 0.3 & 0.4 \\
\hline C & 0.8 & 0.9 & 0.9 & 0.8 & 0.6 & 0.7 & 0.8 & 0.9 \\
\hline
\end{tabular}

The reliability of each supplier is represented by a set of opinion. Table 12 gives the average of opinions.

Table 12 Average of opinions

\begin{tabular}{|c|c|}
\hline Supplier & $\begin{array}{c}\text { Average of } \\
\text { Opinions }\end{array}$ \\
\hline A & 0.275 \\
\hline B & 0.562 \\
\hline C & 0.800 \\
\hline
\end{tabular}

The multiplication of these averages presented in Table 13.

by the note (as given in Table 10) is

Table 13 Final note after the "Discounting" method

\begin{tabular}{|c|c|}
\hline Supplier & Final note \\
\hline A & $0.657 * 0.275=0.180$ \\
\hline B & $0.109 * 0.562=0.061$ \\
\hline C & $0.332 * 0.800=0.265$ \\
\hline
\end{tabular}

We notice that the higher note is attributed to the third supplier $C$ with value 0.265 . But, it also remains insufficient since it is the methods which do not take into account the constraint imposed by the supplier. 


\section{- Method with constraint}

Knowing that each supplier depends on one or more constraints, and then we will take as constraint example such as the capacity production (number of computers produced by week). Table 14 summarizes the capacity production for each supplier.

Table 14 Constraint for three suppliers

\begin{tabular}{|c|c|}
\hline Supplier & $\begin{array}{c}\text { Capacity } \\
\text { production }\end{array}$ \\
\hline A & 600 \\
\hline B & 800 \\
\hline C & 300 \\
\hline
\end{tabular}

The customer formulated his request for a quantity of 500 computers. So by applying the MC method which is an indicator of decision, if a customer needs a quantity lower or equal to 300 computers then the best decision would be to buy $\mathrm{C}$ since it presents the higher note. On the other hand, if a customer needs a quantity higher than 300 then it is necessary to choose to buy from $\mathrm{A}$ or $\mathrm{B}$, since the supplier $\mathrm{C}$ is limited by a constraint (capacity production). In the same manner, we notice that the note of supplier A (using FAHP methods, as given in Table 13) is higher than the supplier B. Consequently, the 500 computers requested by the customer will be bought by supplier A.

\section{- Method with fuzzy constraint}

With the MCF method, the introduction of fuzzy logic is made based on the constraint which is the production capacity. This data changes a strict number to a fuzzy number which is illustrated by a membership function. Customer requests and the unfolding algorithm remain the same. Table 15 summarizes these data.

Table 15 Fuzzy constraint for three suppliers

\begin{tabular}{|c|c|c|c|}
\hline Supplier & \multicolumn{3}{|c|}{$\begin{array}{c}\text { Production } \\
\text { Capacity }\end{array}$} \\
\hline A & 480 & 600 & 650 \\
\hline B & 620 & 800 & 910 \\
\hline C & 180 & 300 & 550 \\
\hline
\end{tabular}

So the linguistic variable used for the resolution of our supplier selection and evaluation problem is the capacity production defined as follows: (Capacity production, $\{\mathrm{A}, \mathrm{B}, \mathrm{C}\}, \mathrm{X}$ ), with: $\mathrm{X}$ is the universe discourse defined on the interval $[180,910]$. Figure 4 shows the membership functions of the capacity production. 


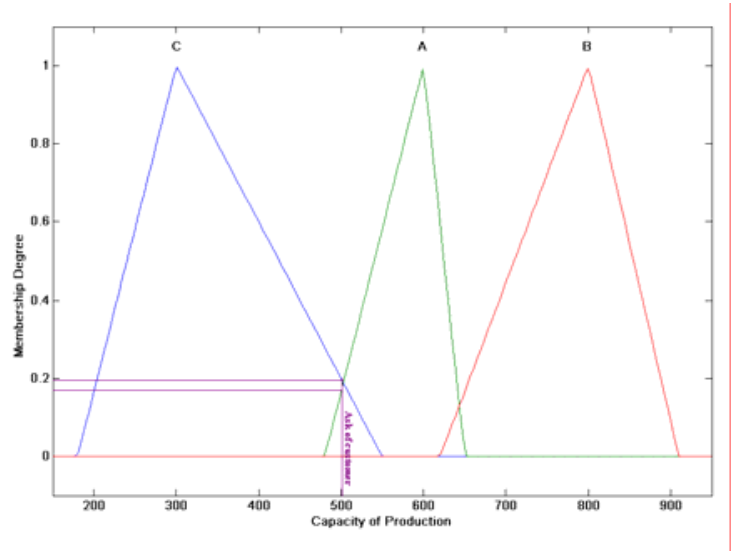

Fig. 4 Membership functions of the capacity production

In this case, the final decision will change after introducing the fuzzy logic. This is important in order to find solutions with the inaccuracy and uncertainty problems. In this case, it is obvious to choose the supplier $C$ since it has the best note found by FAHP method and that it satisfies the constraint requested by the customer.

\section{CONCLUSION}

The supplier selection and evaluation problem require practical methods. Indeed, the classic approaches were showed certain weaknesses such as the ignorance of the constraint, the external factors and the supplier reliability. This way gives origin to other multi-criteria methods using several criteria at the same time for resolving this problem.

Among these methods, we turned to the multi-criteria methods study such as AHP, FAHP and GP. These methods have demonstrated convincing results for the selection problems. This new approach is based essentially on the combination of the multi-criteria methods with fuzzy logic and reliability concept. These criteria are essential for profitability judgment.

\section{REFERENCES}

[1] A. W Labibe, M. R. Abdi.: "Grouping and selecting products: the design key of reconfigurable manufacturing systems (RMSs)”, International Journal of Production Research, Vol. 42, 2004, pp. 521-546.

[2] C. Liang-Hsuan, T. Feng-Chou: "Fuzzy goal programming with different importance and priorities", European Journal of Operational Research, Vol. 133, 2001, pp. 548-556.

[3] G. Wanga, S. Huang, J. Dismukesa: "Product-driven supply chain selection using integrated multi-criteria decision-making methodology", International journal of production economics, 2003, pp. 1-15.

[4] J. Liu, F.Y. Ding, V. Lall: "Using Data Envelopment Analysis to compare supplier selection and performance improvement”, Int. Journal Supply Chain Management, Vol. 5, No. 3, 2000, pp. 143-150.

[5] J. Pomerol, S. Barba-Romero: Choice multi-criteria in company, Paris, Hermes, 1993.

[6] J. Yang: "Minimax reference point approach and its application for multi-objective optimisation", European Journal of Operational Research, Vol. 126, 2000, pp. 541-556.

[7] K.J. Zhu, Y. Jing, D.Y. Chang: “A discussion on extent analysis method and application of fuzzy AHP”, European Journal of Operational Research, Vol. 116, 1999, pp. 450-456.

[8] L. Benyoucef, H. Ding, X. Xie: "Supplier selection problem: selection criteria and methods (Theme 4)", Simulation and optimization of complex systems, Project MACSI, No. 4726, Feb 2003, pp. 38. 
[9] L.A. Zadeh: “Fuzzy Sets”, Information and Control, Vol. 8, 1965, pp. 338-353.

[10] M. Gunes, N. Umarosman: "Fuzzy goal programming approach on computation of the fuzzy arithmetic mean", Mathematical and Computational applications, Vol. 10, No.2, 2005, pp. 211-220.

[11] M. G. Iskander: "A fuzzy weighted additive approach for stochastic fuzzy goal programming”, Applied Mathematics and Computation, Vol. 154, 2004, pp. 543-553.

[12] P.T. Harker: "The art and science of decision making: The analytic hierarchy process", in: Golden, B.L., Wasil, E.A., Harker, P.T. (Eds.), the Analytic Hierarchy Process: Applications and Studies Springer, Berlin 1989, pp. 336.

[13] S. Ben Mena.: "Introduction of methods multi-criteria aid for decision", Biotechnology Agron. Soc. Environ, 2000, pp.83-93.

[14] S. Ben Mena: "Computer solution of sensibility analysis for Electre III”, Biotechnology Agron. Soc. Environ, 2001, pp.31-35.

[15] S. Zaim, M. Sevkli, M. Tarim: Fuzzy analytic hierarchy based approach for supplier selection, 2003.

[16] T. Saaty: Decide face a complexity: approach analytic multi-criteria aid for the decision, Modern Edition Company, Paris, 1980, pp. 77-120.

[17] Z.C. Lin, C.B. Yang: "Evaluation of machine selection by the AHP method", Journal of Materials Processing Technology, Vol. 57, No. 3-4, 1996, pp. 253-258.

\section{BIOGRAPHY}

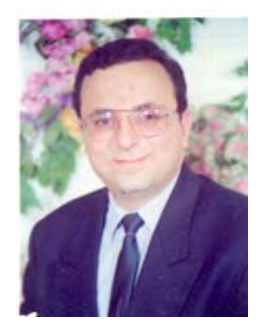

Raouf KETATA was born in Sfax, Tunisia in 1961. He received the Engineering Diploma in electrical engineering from the National School of Engineer in Sfax-Tunisia in 1987 and the Master degree in signal treatment, computer science and automatic in 1988 and the Ph.D. degree in computer science and automatic in 1992 from National Institute of Applied Science in Toulouse-France. From 1988 to 1992, he had a Contract Assistant Post in National Institute of Applied Science in Toulouse-France. From 1992 to 1994, he had an Assistant Professor post in National Atlantic School of Engineer in Genie Electric-France. He is currently an assistant professor in National Institute of Applied Science and Technology - Tunisia and member of Research unit on Intelligent Control, design and Optimization of Complex System (ICOS). His current research interests lie in fuzzy logic, neural networks, genetic algorithms, intelligent systems modelling, and control.

Research Unit: Research unit or Intelligent Control, design and Optimisation of Complex System (ICOS), National School of Engineers of Sfax, National Institute of Applied Science and Technology of Tunis, Tunisia. 


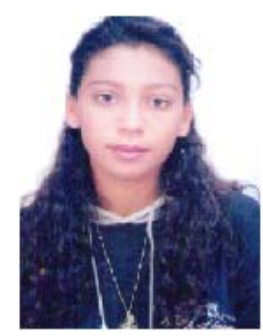

Hajer BEN MAHMOUD was born in Tunis, Tunisia in 1979. She received the Engineering Diploma in industrial computer and automatic from the National Institute of Applied Science and Technology-Tunisia in 2005 and the Master degree in industrial computer and automatic in 2006. She is currently a Contractual Assistant Post in Biotechnology Institute of Monastir-Tunisia. Her current research interests lie in fuzzy logic, genetic algorithms, intelligent systems modelling, and control. 